\title{
Ankle arthritis predicts worse outcome in children with juvenile idiopathic arthritis
}

\author{
Anna-Clara Esbjörnsson ${ }^{1}$, Kristiina Aalto ${ }^{2}$, Eva W Broström ${ }^{1}$, Anders Fasth ${ }^{3}$, Troels Herlin ${ }^{4}$, Susan Nielsen ${ }^{5}$, \\ Ellen Nordal ${ }^{6}$, Marite Rygg ${ }^{7}$, Marek Zak ${ }^{5}$, Lillemor Berntson ${ }^{8 *}$, \\ Nordic Study Group of Pediatric Rheumatology (NoSPeR)
}

From 21st European Pediatric Rheumatology (PReS) Congress

Belgrade, Serbia. 17-21 September 2014

\section{Introduction}

The ankle joint is commonly involved in children with Juvenile Idiopathic Arthritis (JIA) and ankle arthritis predicts a more severe disease according to earlier studies. These studies have mainly been cross-sectional and the results are problematic to generalize to broader populations.

\section{Objectives}

To evaluate the presence of ankle arthritis in children with JIA in a population-based cohort, to describe clinical characteristic in children with ankle arthritis and to evaluate the relation between ankle arthritis and remission status eight years after disease onset.

\section{Methods}

In total 440 children with JIA were included prospectively in a population based cohort study. Data on remission was available for 427 of these children. The presence of ankle arthritis during an eight years follow-up period was analyzed in relation to remission data and clinical characteristics. Remission was defined according to the preliminary criteria by Wallace et al. 2004.

\section{Results}

Of the 440 children with JIA, 251 (57\%) experienced ankle arthritis during the first eight years of disease. Ankle arthritis was least common in the persistent oligoarticular category (25\%) and the ankle joint was most commonly affected in children with the extended oligoarticular (83\%) and polyarticular RF negative (85\%) JIA. Children who

\footnotetext{
${ }^{8}$ Department of Paediatrics, Uppsala University Hospital, Uppsala, Sweden Full list of author information is available at the end of the article
}

developed ankle arthritis, were younger at disease onset (median age 4.5 (IQR 2.0-8.7) vs. 7.3 (IQR 3.5-10.8), $\mathrm{p}<0.001)$ and had more cumulative involved joints (median involved joints 10 (IQR 5-16) vs 2 (IQR 1-5), $\mathrm{p}<0.001$ ), compared to those without ankle arthritis. Hind, mid and forefoot involvement were significantly more common in children with ankle involvement as compared to those without. The OR for not being in remission eight years after disease onset was 2.6 (95\% CI:1.7-3.8, $\mathrm{p}<0.001$ ) if the ankle joint was involved. After adjusting for other joints in the lower extremity the OR for not being in remission was 1.6 (95\% CI: 1.1-2.5, $\mathrm{p}=0.03$ ).

\section{Conclusion}

- Ankle joint arthritis in children with JIA was associated with a young age of onset

- The ankle joint was frequently involved except for the persistent oligoarticular category

- The presence of ankle arthritis was related to failure to achieve remission

\section{Disclosure of interest}

None declared.

\section{Authors' details}

'Department of Women's and Children's Health, The Karolinska Institute, Stockholm, Sweden. 'Department of Paediatrics, Children's Hospital, Helsinki University Hospital, Helsinki, Finland. ${ }^{3}$ Department of Paediatrics, University of Gothenburg, Gothenburg, Sweden. ${ }^{4}$ Department of Paediatrics, Århus University Hospital, Århus, Denmark. ${ }^{5}$ Pediatric Rheumatology Department, Copenhagen University Hospital, Rigshospitalet, Copenhagen, Denmark. ${ }^{6}$ Department of Paediatrics, University Hospital of North Norway, Tromsø, Norway. 'Department of Laboratory Medicine, Children's and Women's Health, and Department of Pediatrics, Norwegian University of Science and Technology, St.Olav's Hospital, Trondheim, Norway. ${ }^{8}$ Department of Paediatrics, Uppsala University Hospital, Uppsala, Sweden. 
Cite this article as: Esbjörnsson et al:: Ankle arthritis predicts worse outcome in children with juvenile idiopathic arthritis. Pediatric Rheumatology 2014 12(Suppl 1):P33.

Submit your next manuscript to BioMed Central and take full advantage of:

- Convenient online submission

- Thorough peer review

- No space constraints or color figure charges

- Immediate publication on acceptance

- Inclusion in PubMed, CAS, Scopus and Google Scholar

- Research which is freely available for redistribution

Submit your manuscript at www.biomedcentral.com/submit
C Biomed Central 